\title{
Students' Beliefs About Mathematics Learning and Problem Solving: The Case of Grade Eleven Students in West Arsi Zone, Ethiopia
}

\author{
Mulugeta Atnafu Ayele ${ }^{1,2}$, Tesfu Belachew Dadi ${ }^{2}$ \\ ${ }^{1}$ Department of Science \& Mathematics Education, Addis Ababa University, Addis Ababa, Ethiopia \\ ${ }^{2}$ Department of Mathematics, Medda Walabu University, Oromiya, Ethiopia
}

Email address:

ayatmu@yahoo.com (M. A. Ayele), tesfu.belachew@yahoo.com (T. B. Dadi)

\section{To cite this article:}

Mulugeta Atnafu Ayele, Tesfu Belachew Dadi. Students' Beliefs About Mathematics Learning and Problem Solving: The Case of Grade Eleven Students in West Arsi Zone, Ethiopia. Education Journal. Vol. 5, No. 4, 2016, pp. 62-70. doi: 10.11648/j.edu.20160504.14

Received: May 20, 2016; Accepted: May 26, 2016; Published: June 30, 2016

\begin{abstract}
Currently, there is a strong political focus in Ethiopia on science, engineering, and mathematics. This to be efficient and practical strong mathematics knowledge, which is built through effective mathematics learning and problem solving, is momentous. For this in turn students' beliefs about mathematics learning and problem solving play an important role; since students' beliefs are vital forces in students' mathematics learning and problem solving. Therefore, investigating students' beliefs about mathematics learning and problem solving is essential in educational research. To address the problem quantitative approach using survey design was employed. The data was collected from four schools in West Arsi Zone using multistage sampling. The quantitative data obtained was analyzed using mean and independent samples t-test. Consequently, this study displayed that students' beliefs about mathematics learning, and students' beliefs about mathematics problem solving, were neutral; and there was statistically significant difference in students' beliefs about mathematics learning and problem solving according to stream, and parents' residence. However, even though the mean of students' beliefs about mathematics learning and problem solving for male students was greater than that of female students, there was no statistically significant difference between male and female students in their beliefs about mathematics learning and problem solving.
\end{abstract}

Keywords: Beliefs, Mathematics, Learning, Problem Solving

\section{Introduction}

For education to be problem solver and functional it should lay on the strong education system that creates well trained and well equipped man power that can suggest a solution for the problem of the society. This in turn lays on the strong foundation of science, engineering, and mathematics that can contribute a lot in building a bridge to transform the people from the level of poverty to the level of prosperity. That is why currently, there is a strong political focus in Ethiopia on science, engineering, and mathematics [1]. This to be efficient and practical strong mathematics knowledge, which is built through effective mathematics learning and problem solving, is momentous. For this in turn, student' beliefs about mathematics learning and problem solving, that is, the beliefs students hold about what are productive and counterproductive learning and problem solving strategies in mathematics, play an important role.

\subsection{Literature Review}

In learning mathematics research indicates that some students give high emphasis for memorizations, others associate ability for being successful in mathematics. For example, Mapolelo conducted a research on beliefs about the nature of mathematics, mathematics learning and factors that impact on learning mathematics in three rural senior secondary schools in Botswana [2]. Finding revealed that students feel learning by memorization determines their success in solving problems. Students also believed that one aspect of becoming successful in mathematics is to understand and to apply memorized rules and procedures when solving mathematical problems [3].

Moreover, related to mathematics learning and problem solving, many students also have beliefs that diminish their 
motivation and actually hinder interest in, and understanding of the subject. Typical examples of such student beliefs are:

- Mathematics problems have one and only one right answer.

- There is only one correct way to solve any mathematics problem, usually the rule the teacher has most recently demonstrated to the class.

- Ordinary students cannot expect to understand mathematics; they expect simply to memorize it and apply what they have learned mechanically and without understanding.

- Mathematics is a solitary activity, done by individuals in isolation.

- Students who have understood the mathematics they have studied will be able to solve any assigned problem in five minutes or less.

- The mathematics learned in school has little or nothing to do with the real world. [4]

The above beliefs affect students' perseverance and motivation in the process of learning concepts of mathematics and solving problems that cannot be understood easily and solved quickly. For example, students who believe problems must be solvable in five minutes or less conclude that one should give up on any problem which cannot be completed in five minutes [5]. They also challenge the teaching process. Because, they may pose difficulties for teachers who may hold constructivist views of mathematics and want to teach mathematics in a constructivist manner [2].

Indeed, students can develop the above beliefs due to different reasons. For instance, they may hold due to the communication of an absolutist view in school by giving students mainly unrelated routine mathematical tasks which involve the application of learnt procedures, and by stressing that every task has a unique, fixed and objectively right answer, coupled with disapproval and criticism of any failure to achieve this answer. Also, students can develop them due to their experiences in previous classes, in particular, in elementary and junior high school. For example, students believe that all mathematics problems can be completed in five minutes or less since these students have the experience to complete ten or more exercises in elementary and junior high school, so that problems which require sustained thought are rare, and most text books word problems are of the 1-or 2-step variety that can be solved in one or two minutes [6]. In addition, experiences of learning mathematics in rigid and structured classrooms which include little opportunity for debate or discussion focus on searching for the one right answer, offer limited encouragement to reflect on thinking, expect quick answers, and emphasis timed tests [7].

Problem solving is a scientific process that evolves from understanding the problem to evaluating the solution, and this process is affected by several factors. Among these, one of the most substantial is belief. The students who thought problem solving should be a short process and that they could address it by memorization of rules also believed that problem solving is difficult. In this case not only beliefs affect the problem solving process, but also personal factors such as life experiences [8].

In Ethiopia, mathematics is a prerequisite for admission into university and college areas of study. It is used as a language for science and technology. Indeed, the government of Ethiopia has recently designed a strategy through which $70 \%$ of the university enrollment would be in science and technology, which deserves strong mathematics knowledge [1].

In the study conducted in 2010 on grades 10 and 12 to provide information about learning attainments by students and the factors that determine those attainments in mathematics results across subgroups: gender, region and selected home background variables, it was found that in grade 10 the mean score for mathematics was $34.7 \%$ and only $14.7 \%$ of students in mathematics were able to score $50 \%$ and above [9]. In this article grade 12 the mean score for mathematics was $54.3 \%$ and only $57.7 \%$ of students in mathematics were able to score $50 \%$ and above. One of the reasons indicated for this low performance of students was the beliefs of students' that they have in mathematics.

Therefore, the significance of this study will provide comprehensive overview of students' beliefs about mathematics learning and problem solving; and provide feedback to the concerned bodies (notably government and non-governmental institutions, curriculum designers, mathematics educators, mathematicians, researchers, schools, families, mathematics teachers and students themselves) so that to improve students' beliefs in mathematics education. Moreover, it contributes to further studies being as sources of information.

\subsection{Statement of the Problem}

In Ethiopia, problem of mathematics concept understanding, low skill of problem solving and low students' performance in mathematics are widely observed in secondary schools. The problems are associated with problem of students' beliefs in mathematics ([10], [11], [9] \& [12]). In addition, in recent years much concern has been expressed about students' reluctance to continue to learn and solve mathematics problems beyond the compulsory years [12]. This is widely observed in grade eleven stream choice and in their first year tertiary education department choice [12]. Hence, the above problems related to students' mathematics learning, problem solving, and mathematics achievement demanded studying students' beliefs about mathematics learning and problem solving.

\subsection{Purpose and Research Questions of the Study}

The purpose of this research was to investigate students' beliefs about mathematics learning and problem solving. From aforementioned purpose, the following four major research questions were posed to be addressed:

1. What are the nature of students' beliefs about mathematics learning and problem solving?

2. Is there a significant difference between male and female students' beliefs about mathematics learning and problem solving? 
3. Is there a significant difference between natural science and social science students' beliefs about mathematics learning and problem solving?

4. Is there a significant students' beliefs about mathematics learning and problem solving difference according to their parents' residence?

\section{Materials and Methods}

\subsection{Research Design}

In this research quantitative approach using a survey design for obtaining descriptive statistics was employed [13].

\subsection{Population and Sampling}

This study was conducted in West-Arsi zone, one of the 19 zones of Oromia National Regional State in Ethiopia. All grade eleven students from government schools of West Arsi Zone were constitute the population of the study. Regarding sampling for data collection using mathematics belief scale, multistage sampling was used. Accordingly, Dodola, Gedeb Hasasa, Shashemene and Arsi Negele preparatory schools were selected by lottery method. There were 2046 (1247 males and 799 females; 1233 natural science and 813 social science) students in the four sampled preparatory schools when the sample was taken. Following the selection of the four sampled preparatory schools, it was made clear that the students were assigned randomly without any discrimination in each section. Hence, sections were selected using lottery method to collect data using mathematics belief scale. The researcher then considered all students in the selected sections for data collection. The selected students of the study were 600 students in which all were the members of the above selected schools and selected sections. However, from 600 respondents the participants who have properly responded were 545 (325 males and 220 females). The responses of 55 respondents were dropped due to inconsistency and incomplete responses.

\subsection{Instrument of Data Collection}

In order to address the research questions of this study mathematics belief scale was used and adapted from [14]. The mathematics belief scale has two belief components: students' beliefs about mathematics learning and students' beliefs about mathematics problem solving, each contain eight items. Items of students' beliefs about mathematics learning address memorization, natural ability, effort, and group work in mathematics learning, whereas items of students' beliefs about mathematics problem solving address patience and persistence in solving mathematics problem, nature of methods of solving, nature of solutions of mathematics problem, and possibility of solving mathematics problems without remembering formulas. Also, eight of the items of the mathematics belief scale are positive and eight of the items are negative. In the scale the respondents were asked to complete on a five point Likert Scale: "Strongly agree", "Agree", "Undecided", "Disagree", and "Strongly Disagree", and for the positive items rated as 5, 4, 3, 2, and 1 respectively; while for negative item the rating was reversed.

\subsection{Validity and Reliability}

In this research, to maintain both the content and the face validity of the mathematics belief scale, it was repeatedly checked by colleagues and then by advisors. Also, pilot-test was conducted on 40 grade 11 students of Didea Preparatory School in East Arsi Zone, which was selected by simple random sampling. Thus, the responses of 40 respondents of the pilot study and 545 respondents of the main data were used for discussing the reliability statistics of students' beliefs about mathematics learning and students' beliefs about mathematics problem solving. Accordingly, the reliability statistics (Cronbach's Alpha) for students' beliefs about mathematics learning and problem solving (pilot $=.866$, main data $=.954$ ), students' beliefs about mathematics learning (pilot $=.847$, main data $=.884$ ) and students' beliefs about mathematics problem solving (pilot $=.860$, main data $=.955$ ) were greater than 0.7 , which indicated that the mathematics belief scale was high internal consistence reliability.

\subsection{Method of Data Analysis}

The skewness values (statistics) of all the belief scale items of the main study are between -1 and 1 . Accordingly, the data distribution is approximately normal [15]. Therefore, in accordance with the objective of the study and the research questions, and the normality of the data, mean, and independent samples t-test were employed.

\section{Results and Discussions}

\subsection{The Nature of Students' Beliefs About Mathematics Learning and Problem Solving}

The analysis of students' beliefs about mathematics learning and problem solving was based on low (strongly negative beliefs: 1.0 to 1.4 ; and negative beliefs: 1.5 to 2.4 ); medium (neutral: 2.5 to 3.4 ) and high (positive beliefs: 3.5 to 4.4; and strongly positive beliefs: 4.5 to 5.0 ). Based on the analysis key of beliefs, the level of students' beliefs about mathematics learning and problem solving is indicated in Table 1.

Table 1. The Nature of Students' Beliefs about Mathematics Learning and Problem Solving.

\begin{tabular}{|c|c|c|c|c|c|}
\hline Belief Category & $\mathbf{N}$ & M & SD & Level & Description of levels \\
\hline Students' beliefs about mathematics learning and problem solving & 545 & 3.05 & .67 & Medium & Neutral \\
\hline Students' beliefs about mathematics learning & 545 & 3.29 & .92 & Medium & Neutral \\
\hline Students' beliefs about mathematics problem solving & 545 & 2.80 & 1.19 & Medium & Neutral \\
\hline
\end{tabular}


According to this finding, the nature of students' beliefs about mathematics learning and problem solving (Mean = 3.05; SD =.67), the nature of students' beliefs about mathematics learning (Mean = 3.29; SD =.92), and students' beliefs about mathematics problem solving (Mean $=2.80$; SD $=1.19$ ) denote as medium level. That is, the nature students' beliefs about mathematics learning and problem solving are neutral; the nature of students' beliefs about mathematics learning; and students' beliefs about mathematics problem solving is neutral, which are neither positive nor negative beliefs. The mean of students' beliefs about mathematics learning is greater than the mean of students' beliefs about mathematics problem solving. Moreover, the mean score of students' beliefs about mathematics problem solving was low.

One possible explanation for this is that, the students' beliefs about self in mathematics education in general, that is the beliefs students hold to be true about themselves and about their academic potentialities related to mathematics were low. In particular, as it was found in this research, students' self efficacy beliefs and students' task value beliefs in mathematics education are low. In line with this Zimmerman and Campillo indicated that students self beliefs in mathematics, in particular their confidence and selfefficacy are predictive of persistence and effort during problem solving [16]. Furthermore, students' did not want to exert much effort in problem solving. This is due to their low intrinsic goal orientation. In line with this research indicated that students with intrinsic goals are inclined to exert more effort and are more likely to persistent with difficult tasks than those with extrinsic goals [17].

However, all students did not have neutral beliefs about mathematics learning and mathematics problem solving. To see this consider Table 2 that indicates the percentage of respondents in each level based on average score of components of students' beliefs about mathematics learning and mathematics problem solving.

Table 2. Percentage of Respondents in Each Level of Students'Beliefs about Mathematics Learning and Mathematics Problem Solving.

\begin{tabular}{|c|c|c|c|c|c|c|}
\hline \multirow{2}{*}{ Belief Components } & \multirow{2}{*}{$\mathbf{N}$} & \multicolumn{5}{|c|}{ Percentage of Respondents in Each Level } \\
\hline & & Strongly positive & Positive & Neutral & Negative & Strongly negative \\
\hline Students' beliefs about mathematics learning & 545 & 9.2 & 44.0 & 22.8 & 23.8 & 0.2 \\
\hline Students' beliefs about mathematics problem solving & 545 & 11.0 & 25.9 & 15.4 & 38.2 & 9.5 \\
\hline
\end{tabular}

From Table 2, it can be seen that all students were not assigned in the same neutral level of beliefs. Related to students' beliefs about mathematics learning, there were only $22.8 \%$ of students having neutral beliefs, which is neither positive nor negative beliefs; the remaining $77.2 \%$ of students are in the other levels. That is about $9.2 \%$ of them had strongly positive beliefs, $44.0 \%$ of them had positive beliefs, while $23.8 \%$ of them had negative beliefs, and $0.2 \%$ had strongly negative beliefs. Thus, more than half $(53.2 \%)$ of the students had either strongly positive or positive beliefs about mathematics learning. On the other hand, regarding mathematics problem solving only $15.4 \%$ of students had neutral beliefs, which is neither positive nor negative beliefs; the remaining $84.6 \%$ of students were in the other levels. That is about $11.0 \%$ of them had strongly positive beliefs, $25.9 \%$ of them had positive beliefs, whereas $38.2 \%$ of them had negative beliefs, and $9.5 \%$ of them had strongly negative beliefs.

Table 2 also indicated that nearly half $(47.7 \%)$ of the students had either negative or strongly negative beliefs about mathematics problem solving. One possible explanation for this is that due to students' low self efficacy beliefs, task value beliefs and intrinsic goal orientation beliefs about mathematics, which they are very important for students to deeply engaged in doing mathematics problems, to be willing to tackle new challenges, to demonstrate high levels of confidence in their abilities and to persist at doing the problem for a longtime [18]. In addition, when students intrinsically value an activity they often become deeply engaged in it and can persist at it for a longtime [18]. The other reason for high percentage of students with negative or strongly negative beliefs about mathematics problem solving underlined in the questionnaire, interview and focused group discussion was due to their problem related to English language. The students learned mathematics up to grade eight in local language; they have started to learn mathematics in English in grade nine. This situation influenced their understanding of the mathematics problem solving. In line with this Causapin indicated that use of a second language in the mathematics classroom negatively affected confidence and performance [19]. Indeed, a recent study found that it was more beneficial to use the first language in learning mathematics [20]. Moreover, analyzing the percentage of the responses on each positive item of students' beliefs about mathematics learning and students' beliefs about mathematics problem solving as indicated in Table 3.

Table 3. Percentage of Respondents' Responses in the Five Point Likert Scale for Each Positive Item of Students' Beliefs about Mathematics Learning and Mathematics Problem Solving.

\begin{tabular}{|c|c|c|c|c|c|c|}
\hline \multirow{2}{*}{ Belief Items } & \multirow{2}{*}{$\mathbf{N}$} & \multicolumn{5}{|c|}{ Percentage of Respondents' Responses } \\
\hline & & Strongly Agree & Agree & Undecided & Disagree & Strongly Disagree \\
\hline Mathematics learning requires memorizing formulas & 545 & 11 & 45.5 & 13.6 & 22.6 & 7.3 \\
\hline Natural talent is very important to learn mathematics & 545 & 10.5 & 33.6 & 23.3 & 23.1 & 9.5 \\
\hline Individual effort is very important to learn mathematics & 545 & 9.5 & 39.2 & 17.4 & 25.1 & 8.6 \\
\hline Group work facilitates the learning of mathematics & 545 & 6.8 & 53.9 & 29.9 & 8.8 & 0.6 \\
\hline I try mathematics problems until I have the solution & 545 & 17.8 & 21.8 & 12.8 & 19.3 & 28.2 \\
\hline
\end{tabular}




\begin{tabular}{|c|c|c|c|c|c|c|}
\hline \multirow{2}{*}{ Belief Items } & \multirow{2}{*}{$\mathbf{N}$} & \multicolumn{5}{|c|}{ Percentage of Respondents' Responses } \\
\hline & & Strongly Agree & Agree & Undecided & Disagree & Strongly Disagree \\
\hline $\begin{array}{l}\text { There are several ways to find the solution of a mathematics } \\
\text { problem }\end{array}$ & 545 & 22.0 & 19.8 & 13.9 & 28.3 & 16.0 \\
\hline Mathematics problem can have more than one right answer & 545 & 10.0 & 16.7 & 20.7 & 35.8 & 16.9 \\
\hline $\begin{array}{l}\text { Mathematics problems can be solved without remembering } \\
\text { formulas }\end{array}$ & 545 & 10.8 & 24.6 & 14.5 & 25.5 & 24.6 \\
\hline
\end{tabular}

As it can be seen from Table 3, related to students' beliefs about mathematics learning, in each positive items the sum of the percentages of respondents who reported that strongly agree and agree is greater than both the percentages of respondents who reported that undecided and the sum of the percentages of respondents who reported that disagree and strongly disagree. For example, more than half of the respondents $(56.5 \%)$ believed that mathematics learning requires memorizing formulas, while only $29.9 \%$ of them either disagree or strongly disagree with that; $41.1 \%$ of them believed that natural talent is very important to learn mathematics, $32.6 \%$ of them either disagree or strongly disagree with that; $48.7 \%$ of them believed that individual effort is very important to learn mathematics; while $33.7 \%$ of them either disagree or strongly disagree with that; and more than half $(60.7 \%)$ of them believed that group work facilitates the learning of mathematics, while only $9.4 \%$ of them either disagree or strongly disagree with that. Thus, more than half of the students in this study believed that mathematics learning requires memorizing formulas, and group work facilitates the learning of mathematics.

One possible explanation for students' high emphasis on memorization in learning mathematics is due to the lecture oriented method of mathematics teaching. Students indicated that the mathematics class is often dominated by the subject teacher's routine activities which emphasizes on rules and formulas, that is, more on procedural content knowledge than on conceptual knowledge. There is no time for students to engage in the teaching activities to construct their own understanding; they rather expected to memorize the contents covered in class by the subject teacher and its formulas outside the class. Also, lack of consideration from mathematics teachers and students' poor time management contributed for students' high emphasis on memorization in learning mathematics. Students who are required to memorize methods and procedures in mathematics will inevitably believe that mathematics is mainly a matter of following disconnected rules and symbols, and might have more to do with gaining approval than with making sense of mathematics [2].

Also the percentage of students who believed that natural talent is very important to learn mathematics and individual effort is very important to learn mathematics is greater than $40 \%$. The result of students' beliefs obtained in this research related to natural talent is not consistent to the articles [10] and [21]. In an option paper presented at the technical workshop on science and mathematics secondary education in Africa follow-up program underlined that students believed science and mathematics education requires special natural talents that are not normally acquired through learning [10]. Also, Ignacio, Blanco \& Barona indicated that students believed learning mathematics requires a "special ability" that is not always within everyone's reached [21]. However, despite the fact that more than $40 \%$ of students believed both natural talent and individual effort are very important in learning mathematics, the percentage of students who believed that natural talent is very important less than the percentage of students who believed that individual effort is very important to learn mathematics. Besides, as indicated in the focused group discussion comparing natural talent and effort students underlined that effort is very important than natural talent in learning mathematics. Moreover, in this study most of the students believed that group work facilitates the learning of mathematics. This is in agreement with Causapin, in which students believed that group work served as relief because it minimize the "fear" created by explaining their answers in front of everybody that greatly affected their ability; and increased their confidence and made learning easier inside the classroom [19].

On other hand, related to the positive items of students' beliefs about nature of mathematics problem solving in each belief item the sum of the percentages of respondents who reported that strongly agree and agree is greater than the percentage of respondents who reported that undecided, but less than the sum of the percentages of respondents who reported that disagree and strongly disagree. For example, $39.6 \%$ of the students were either strongly agree or agree with the item "I try mathematics problems until I have the solution", while about $47.5 \%$ of them either disagree or strongly disagree with that; $41.8 \%$ of them believed that there are several ways to find the solution of a mathematics problem, while $44.3 \%$ of them either disagree or strongly disagree with that; only $26.7 \%$ of them believed that mathematics problem can have more than one right answer; while more than half $(52.7 \%)$ of them either disagree or strongly disagree with that; and $35.4 \%$ of them believed that mathematics problems can be solved without remembering formulas, while about half (50.1\%) of them either disagree or strongly disagree with that.

Thus, more than half of students in this study believed that mathematics learning requires memorizing formulas, group work facilitates the learning of mathematics, mathematics problem cannot have more than one right answer, and mathematics problems cannot be solved without remembering formulas. This indicated that many students in this study attached mathematics with memorization, one correct answer, one way method and formula bound for solving mathematics problems. Also, quite a large number of students $(47.5 \%)$ either disagreed or strongly disagreed with the item "I try mathematics problems until I have the solution". In this case there is a tendency to respond to this 
item in a slightly more negative way. That is quite a large number of students do not have patience in doing mathematics problems. This is not in agreement with [22]. One possible explanation for lack of patience in solving mathematics problem is that students believed that mathematics problems must be solvable in few minutes so that they give up on any problem which cannot be completed in few minutes. Students develop such beliefs due to their previous experience that normal homework and test problems should be solved in a few minutes, and if not they should not waste time on them, as they think that they would never find the solution. Also, students develop such beliefs due to their experiences to complete 10 or more exercises in elementary and junior high school so that problems which require sustained thought are rare [6].

In addition, quite a large number of students (44.3\%) did not believe that there are several ways to find the solution of a mathematics problem; and the percentage of students who believed that mathematics problem can have more than one right answer is very low $(26.7 \%)$. This is not in agreement with Breiteig, Grevholm, \& Kislenko in which $84 \%$ of pupils disagree that there is just one right answer in mathematics tasks [23]. This belief is due to the fact that these students do not have the chance to explore different possibilities, as they are not patient and persistent to try different alternatives to solve the problems. So they do not have the experience to come across mathematics problems with different answers.
This is also encouraged unintentionally by mathematics teachers' emphasis and acceptance on certainty, fast and correct answers for the given mathematics problems [24], besides the nature of mathematics problems. As Mapolelo these beliefs may pose difficulties for teachers who may hold constructivist views of mathematics and want to teach mathematics in a constructivist manner. Because, the views that students hold on how mathematics problems are solved and on the number of solutions to the mathematics problems are an important component in the culture of the mathematics classroom, since it is linked with the way mathematics is taught and received [2].

\subsection{Gender}

Among 545 respondents whose responses used for the main data analysis, $59.6 \%$ of them were male, and $40.4 \%$ of them were female. The research question of this study related to the gender of students is, 'Is there a significant difference between male and female students' beliefs about mathematics learning and problem solving?' was answered using independent-samples t-test, since the assumptions of independence of male and female response results, the normality of the data and homogeneity of variances of the independent variables were met. Accordingly, the independent t-test was conducted for the above major research question as shown in Table 4.

Table 4. The Independent t-test for Students'Beliefs about Mathematics Learning and Problem Solving with respect to gender.

\begin{tabular}{|c|c|c|c|c|c|c|c|c|}
\hline Belief Category & Group & $\mathbf{N}$ & M & SD & SE & df & t & $\mathbf{p}$ \\
\hline $\begin{array}{l}\text { Students belief about mathematics learning and problem } \\
\text { solving }\end{array}$ & $\begin{array}{l}\text { Gender } \\
\text { Male } \\
\text { Female }\end{array}$ & $\begin{array}{l}325 \\
220\end{array}$ & $\begin{array}{l}3.09 \\
2.99\end{array}$ & $\begin{array}{l}.64 \\
.72\end{array}$ & $\begin{array}{l}.04 \\
.05\end{array}$ & 543 & 1.691 & .091 \\
\hline Students' beliefs about mathematics learning & $\begin{array}{l}\text { Gender } \\
\text { Male } \\
\text { Female }\end{array}$ & $\begin{array}{l}325 \\
220\end{array}$ & $\begin{array}{l}3.30 \\
3.28\end{array}$ & $\begin{array}{l}.91 \\
.95\end{array}$ & $\begin{array}{l}.05 \\
.06\end{array}$ & 543 & .19 & .852 \\
\hline Students' beliefs about mathematics problem solving & $\begin{array}{l}\text { Gender } \\
\text { Male } \\
\text { Female }\end{array}$ & $\begin{array}{l}325 \\
220\end{array}$ & $\begin{array}{l}2.88 \\
2.69\end{array}$ & $\begin{array}{l}1.20 \\
1.18\end{array}$ & $\begin{array}{l}.07 \\
.08\end{array}$ & 543 & 1.76 & .079 \\
\hline
\end{tabular}

$* p<.05$ (2-tailed)

The table above indicated that, even though the mean of students' beliefs about mathematics learning and problem solving for male students (3.09) was greater than that of female students (2.99), there was no statistically significant difference $(t(543)=1.691, p>.05)$ between male and female students in their beliefs about mathematics learning and problem solving. This suggested that there were no statistically significant students' beliefs about mathematics learning and problem solving difference according to gender.

The findings from the independent t-tests in Table 4, also indicated that even though the means are unequal there were no statistically significant differences between male and female students' beliefs about mathematics learning ( $t(543)$ $=.19, p>.05)$, and between male and female students' beliefs about mathematics problem solving $(t(543)=1.76, p>.05)$. In both cases of students' beliefs about mathematics learning, and students' belief about mathematics problem solving, the mean for male students was greater than that of female students. This result is not in agreement with research findings of Fennema \& Sherman and found significant differences in mathematics learning between boys and girls, with the boys learning more effectively due in part to greater confidence in them in their mathematics work [25].

\subsection{Stream}

Among 545 respondents whose responses used for the final data analysis, $60.9 \%$ of them were natural science, and $39.1 \%$ of them were social science. The research question of this study related to stream of students is 'Is there a significant difference between natural science and social science students' beliefs about mathematics learning and problem solving?' was answered using independent-samples t-test, since the assumptions of independence, normality of the data and homogeneity of variances were met and this was indicated in Table 5. 
Table 5. The Independent t-test for Students'Beliefs about Mathematics Learning and Problem Solving with respect to stream.

\begin{tabular}{|c|c|c|c|c|c|c|c|c|}
\hline Belief Category & Group & $\mathbf{N}$ & M & SD & $\overline{S E}$ & df & $t$ & $\bar{p}$ \\
\hline \multirow{3}{*}{$\begin{array}{l}\text { Students belief about mathematics learning and problem } \\
\text { solving }\end{array}$} & Stream & & & & & \multirow{3}{*}{526.50} & \multirow{3}{*}{8.88} & \multirow{3}{*}{$.000^{*}$} \\
\hline & Natural & 332 & 3.23 & .69 & .04 & & & \\
\hline & Social & 213 & 2.76 & .53 & .04 & & & \\
\hline \multirow{3}{*}{ Students' beliefs about mathematics learning } & Stream & & & & & \multirow[t]{2}{*}{540.92} & \multirow[t]{2}{*}{-3.56} & \multirow[t]{2}{*}{$.000 *$} \\
\hline & Natural & 332 & 3.19 & 1.03 & .06 & & & \\
\hline & Social & 213 & 3.45 & .70 & .05 & \multirow{3}{*}{522.88} & \multirow{3}{*}{13.78} & \multirow{3}{*}{$.000^{*}$} \\
\hline \multirow{2}{*}{ Students' beliefs about mathematics problem solving } & $\begin{array}{l}\text { Stream } \\
\text { Natural }\end{array}$ & 332 & 3.27 & 1.13 & .06 & & & \\
\hline & Social & 213 & 2.08 & .88 & .06 & & & \\
\hline
\end{tabular}

$* p<.05$ (2-tailed)

The findings from the independent t-tests in Table 5 indicated that there was statistically significant difference $(t(526.50)=8.88, p<.05)$ between natural and social science students in their beliefs about mathematics learning and problem solving favoring natural science students'. This suggested that there were statistically significant students' beliefs about mathematics learning and problem solving difference according to stream.

Similarly, the findings from the independent t-tests in Table 5, showed that there were statistically significant differences between natural and social science students' beliefs about mathematics learning $(t(540.92)=-3.56, p$ $<.05)$ and students' beliefs about mathematics problem solving $(t(522.88)=13.78, p<.05)$. In case of students' beliefs about mathematics learning, the mean of natural science students is less than that of social science students; where in students' beliefs about mathematics problem solving, the mean of natural science students is greater than that of social science students. This is due to the believe difference observed in each item contained in students' beliefs about mathematics learning and students' beliefs about mathematics problem solving. In case of students' beliefs about mathematics learning, the items address memorization, natural ability, effort, and group work in mathematics learning. In all items of students' beliefs about mathematics learning except the items addressing effort, social science students are more agree on the importance of them than natural science students. However, on the items addressing effort, natural science students give high emphasis for it than social science students. In contrast, on the items contained in students' beliefs about mathematics problem solving, which they address patience and persistence in solving mathematics problem, nature of methods of solving, nature of solutions of mathematics problem, and possibility of solving mathematics problems without remembering formulas, natural science students revealed relatively better mean values in all items.

\subsection{Parents' Residence}

Among 545 respondents, whose responses used for the final data analysis, $56.3 \%$ of them are students' whose parents are in urban, and $43.7 \%$ of them are students, whose parents are in rural. The research question of this study related to parents' residence of students is 'Is there a significant students' beliefs about mathematics learning and problem solving difference according to their parents' residence?' was answered using independent-sample t-test, since the assumptions of independence, normality of the data and homogeneity of variances were met and the result was illustrated in Table 6.

Table 6. The Independent t-test for Students' Beliefs about Mathematics Learning and Problem Solving with respect to parents 'residence.

\begin{tabular}{|c|c|c|c|c|c|c|c|c|}
\hline Belief Category & Group & $\mathbf{N}$ & M & SD & SE & df & $\mathbf{t}$ & $\mathbf{p}$ \\
\hline \multirow{3}{*}{$\begin{array}{l}\text { Students belief about mathematics learning and } \\
\text { problem solving }\end{array}$} & Parents' Residence & & & & & \multirow[t]{3}{*}{543} & \multirow[t]{3}{*}{3.29} & \multirow[t]{3}{*}{$.001^{*}$} \\
\hline & Urban & 307 & 3.13 & .67 & .04 & & & \\
\hline & Rural & 238 & 2.94 & .66 & .04 & & & \\
\hline \multirow{3}{*}{ Students' beliefs about mathematics learning } & Parents' Residence & & & & & \multirow{3}{*}{543} & \multirow{3}{*}{2.46} & \multirow{3}{*}{$.014^{*}$} \\
\hline & Urban & 307 & 3.38 & .94 & .05 & & & \\
\hline & Rural & 238 & 3.18 & .89 & .06 & & & \\
\hline \multirow{3}{*}{$\begin{array}{l}\text { Students' beliefs about mathematics problem } \\
\text { solving }\end{array}$} & Parents' Residence & & & & & \multirow[t]{3}{*}{543} & \multirow[t]{3}{*}{1.77} & \multirow[t]{3}{*}{.077} \\
\hline & Urban & 307 & 2.90 & 1.17 & .07 & & & \\
\hline & Rural & 238 & 2.70 & 1.21 & .08 & & & \\
\hline
\end{tabular}

$* p<.05$ (2-tailed)

The finding from the independent t-tests of Table 6 indicated that there was statistically significant difference $(t(543)=3.29, p<.05)$ between students' beliefs about mathematics learning and problem solving according to parents' residence. Indeed, the mean for students' beliefs about mathematics learning and problem solving whose parents were in urban was greater than that of students' whose parents were in rural. This suggested that there were statistically significant students' beliefs about mathematics learning and problem solving difference according to residence of their parents.

Moreover, the findings from the independent t-tests in 
Table 6 also indicated that there was statistically significant difference $(t(543)=2.46, p<.05)$ between students' beliefs about mathematics learning according to parents' residence favoring students' whose parents are in urban. Also, in all items contained in students' beliefs about mathematics learning, which address memorization, natural ability, effort, and group work, the mean of students' whose parents are in urban was greater than that of students' whose parents are in rural. Interestingly, the mean difference between students whose parents in urban and in rural on the item, "group work facilitates the learning of mathematics", was very small (0.1).

On the other hand, the table showed that even though the mean of students' whose parents are in urban was greater than the mean of students' whose parents are in rural, there was no statistically significant difference $(t(543)=1.77$, $p>.05$ ) between students' beliefs about mathematics problem solving according to parents' residence. Also, on the items of students' beliefs about mathematics problem solving, which address patience and persistence in solving mathematics problem, nature of methods of solving, nature of solutions of mathematics problem, and possibility of solving mathematics problems without remembering formulas, both students' whose parents are in urban and in rural have expressed nearly similar beliefs, even though the mean of students' beliefs whose parents are in urban was greater than the mean of students' beliefs whose parents are in rural on each item.

\section{Conclusions and Recommendations}

\subsection{Conclusions}

The objective of this study was to investigate grade eleven students' beliefs about mathematics learning and problem solving. Specifically, the study was to analyze whether there are significant students' beliefs about mathematics learning and problem solving difference according to gender, stream, and parents' residence. Therefore, from the result and discussion the following findings were obtained:

1). Regarding students' beliefs about mathematics learning, and students' beliefs about mathematics problem solving, were neutral, which is neither positive nor negative.

2). The study revealed that there were no statistically significant differences between male and female students' beliefs about mathematics learning and problem solving, students' beliefs about mathematics learning and students' beliefs about mathematics problem solving. In both cases the mean for male students was greater than that of female students.

3). This study displayed that there were statistically significant stream difference in students' beliefs about mathematics learning and problem solving, students' beliefs about mathematics learning and students' beliefs about mathematics problem solving. In case of students' beliefs about mathematics learning, the mean for natural science students was less than that of social science students; where as in case of students' beliefs about mathematics problem solving the mean for natural science students was greater than that of social science students.

4). Regarding students' beliefs about mathematics learning and problem solving, students' beliefs about mathematics learning and students' beliefs about mathematics problem solving related to parents' residence, this study revealed that there were statistically significant belief differences according to residence of their parents. In both cases the mean for students' whose parents' are in urban was greater than that of students' whose parents' are in rural.

\subsection{Recommendations}

In order to improve students' beliefs about mathematics learning and problem solving and also narrow the difference between different groups of students about mathematics learning and problem solving the following recommendations were proposed.

1). Help students to develop the culture of working hard and working together, and to manage their time wisely so that study mathematics before mathematics concepts piled up.

2). Help students to associate the mathematics learned in school with the real world problem and to show students that mathematics has many applications within the society.

3). Help students depart/split from rule oriented way of solving mathematics problem by memorizing formulas. Instead, help students to develop the culture to try different alternatives in solving mathematics problems and possibility of solving mathematics problems without remembering formulas, and develop perseverance and patience in solving mathematics problem from the previous classes, in particular, in elementary and junior high school.

4). Help students develop the awareness that mathematics problems have more than one right answer. In this case mathematics teachers avoid giving students mainly unrelated routine mathematical tasks which involve the application of learnt procedures, and by stressing that every task has a unique, fixed and objectively right answer.

5). Mathematics teachers create a teaching environment so that students learn mathematics in flexible and semi structured classrooms which include many opportunity for debate or discussion focus on searching for the different answers. Mathematics teachers not expect quick answers, and not emphasis timed tests, instead it is good to encourage students to give emphasis on thinking and concept understanding,

6). In general it is important male and female students, natural science and social science students, and students whose parents' are in urban and in rural to take the first initiatives to improve their beliefs about mathematics learning and problem solving. 


\section{References}

[1] MoE (2008) Annual Intake and Enrolment Growths and Professional and Program Mix of Ethiopian Public Higher Education: Strategy and Conversion Plan, 2001-2005. Addis Ababa.

[2] Mapolelo, D. C. (2009) Students' experiences with mathematics teaching and learning: listening to unheard voices. International Journal of Mathematical Education in Science and Technology, 40 (3), 309-322.

[3] Presmeg, N. (2002) Beliefs about the nature of mathematics in the bridging of everyday and school mathematical practices. In G. Leder, E. Pehkonen, \& G. Torner (Eds.), Beliefs: A hidden variable in mathematics education? (pp. 293-312).

[4] Schoenfeld, A. H. (1992) Learning to think mathematically: Problem solving, metacognition, and sense making in mathematics. In D. A. Grouws (Ed.), Handbook of research on mathematics teaching and learning, New York: Macmillan, pp. 334-369.

[5] Schoenfeld, A. H. (1988) When good teaching leads to bad results: The disasters of "well-taught" mathematics courses, Educational Psychologist, 23 (2), pp. 145-166.

[6] Nibbelink, W. H., Stockdale, S. R., Hoover, H. D., \& Mangru, M. (1987) Problem solving in the elementary grades: Textbook practices and achievement trends over the past thirty years. Arithmetic Teacher, 35 (1): 34-37.

[7] Shields, D. J. (2005) Teachers have the power to alleviate math anxiety. Academic Exchange Quarterly, 9 (3), 326-330.

[8] Ozturk T. \& Guven B. (2016). Evaluating Students' Beliefs in Problem Solving Process: A Case Study. Karadeniz Technical University, TURKEY; Eurasia Journal of Mathematics, Science \& Technology Education, 2016, 12 (2), 411-429.

[9] NAE (2010) Ethiopian Baseline National Learning Assessment of Grades 10 \& 12 Students. Addis Ababa: NOE/MOE

[10] Asfaw, E., Otore, D., Ayele, T., \& Gebremariam, Z. (2009) Science and mathematics secondary education. An Option paper presented at the Technical Workshop on Science and Mathematics Secondary Education in Africa (SEIA) Followup Program, Tunis

[11] Atnafu, M. (2010) Relation between Tenth Grade Students' Attitude and Components of Attitude in Algebra with Algebra Achievement of Addis Ababa Secondary Schools, International Journal for Mathematics Teaching and Learning, Ethiopia.

[12] Belachew, T. (2015) Students' Beliefs In Mathematics Education: The Case of West Arsi Zone, Ethiopia (Doctoral dissertation, Addis Ababa University).

[13] Creswell, J. W. (2014) Research Design: Quantitative, Qualitative, Mixed Methods ( $4^{\text {th }}$ ed.). Thousand Oaks, CA: Sage Publication.
[14] Hannula, M. S., Kaasila, R., Laine, A., \& Pehkonen, E. (2005) The structure of student teacher's view of mathematics at the beginning of their studies. In Proceedings of the Fourth Congress of the European Society for Research in Mathematics Education. Sant Feliu de Guíxols, Spain-17-21 February (pp. 205-214).

[15] Leech, N. L., Barrett, K. C. \& Morgan, G. A. (2005) SPSS for Intermediate Statistics; Use and Interpretation (2nd ed.). Lawrence Erlbaum Associates, Inc. New Jersey, London. Breiteig, T., Grevholm, B., \& Kislenko, K. (2005) Beliefs and attitudes in mathematics teaching and learning. Vurdering $i$ matematikk-Hvorfor og hvordan, 129-138.

[16] Zimmerman, B. J., and Campillo, M., (2003) Motivating SelfRegulated Problem Solvers, in Janet E. Davidson and Robert J. Sternberg (eds.), The Psychology of Problem Solving, New York: Cambridge University Press. Causapin, M. G. A. (2012) Mathematics self-efficacy and its relation to proficiencypromoting behavior and performance (Doctoral dissertation, Columbia University).

[17] Pintrich, P. R., \& Schunk, D. H. (2002) Motivation in education: Theory, research, and applications (2nd ed.). Upper Saddle River, NJ: Merrill/Prentice Hall.

[18] Wigfield, A., \& Cambria, J. (2010) Students' achievement values, goal orientations, and interest: Definitions, development, and relations to achievement outcomes. Developmental Review, 30 (1), 1-35.

[19] Causapin M. G. A (2012). Mathematics Self-Efficacy and its Relation to Proficiency-Promoting Behavior and Performance. $\mathrm{PhD}$ dissertation, Graduate School of Arts and Sciences, Columbia University.

[20] Walter, S., \& Dekker, D. (2011) Mother tongue instruction in Lubuagan: A case study from the Philippines. International Review of Education, 57 (5), 667-683.

[21] Ignacio, N. G., Blanco Nieto, L. J., \& Barona, E. G. (2006) The affective domain in mathematics learning. International Electronic Journal of Mathematics Education, 1 (1), 16-32.

[22] Kislenko, K., Grevholm, B., \& Breiteig, T. (2005). Beliefs and attitudes in mathematics teaching and learning. In I. M. Stedøy (Ed.), Vurdering i matematikk - Hvorfor og hvordan? Fra småskole til voksenopplaering. Nordisk konferanse $i$ matematikkdidaktikk ved NTNU 15. og 16. (pp. 129-138). Trondheim: Nasjonal Senter for Matematikk i Opplæringen.

[23] Breiteig, T., Grevholm, B., \& Kislenko, K. (2005) Beliefs and attitudes in mathematics teaching and learning. Vurdering $i$ matematikk-Hvorfor og hvordan, 129-138.

[24] Lampert, M. (1990) When the problem is not the question and the solution is not the answer: Mathematical knowing and teaching. American Educational Research Journal, 27 (1), 2963.

[25] Fennema, E. \& Sherman, J. (1978) Sex-related differences in mathematics achievement and related factors: a further study. Journal for Research in Mathematics Education, 9 (3), 189203. 